\title{
CELLULAR LOCALIZATION OF THE MOLECULAR FORMS OF ACETYLCHOLINESTERASE IN CULTURED EMBRYONIC RAT MYOTUBES $^{1}$
}

\author{
STEVEN K. BROCKMAN, RONALD J. PRZYBYLSKI, and STEVEN G. YOUNKIN ${ }^{2}$
}

Departments of Pharmacology and Anatomy, Case Western Reserve University School of Medicine, Cleveland, Ohio 44106

Received May 17, 1982; Revised July 12, 1982; Accepted July 12, 1982

\begin{abstract}
Three different methods were used to quantitate the external and intracellular acetylcholinesterase $(\mathrm{AChE})$ in cultured embryonic rat myotubes. The results from these methods were in excellent agreement and showed that one-fourth of the $\mathrm{AChE}$ is external and three-fourths is intracellular in these cells. The molecular forms of AChE in the intracellular and external compartments then were analyzed. To isolate intracellular AChE, external AChE was inactivated irreversibly by treating myotubes at $2{ }^{\circ} \mathrm{C}$ with $10 \mu \mathrm{M}$ methanesulfonyl fluoride and $100 \mu \mathrm{M}$ decamethonium for $1 \mathrm{hr}$. To isolate external $\mathrm{AChE}$, myotubes at $2^{\circ} \mathrm{C}$ were first exposed to $1.0 \mu \mathrm{M}$ echothiophate for $15 \mathrm{~min}$ to protect (diethylphosphorylate) external $\mathrm{AChE}$ and then treated with $1.0 \mathrm{~mm}$ methanesulfonyl fluoride for $30 \mathrm{~min}$ at $37^{\circ} \mathrm{C}$ to inactivate intracellular AChE irreversibly. Control myotubes and myotubes in which the external or intracellular enzyme had been isolated were extracted sequentially to separate globular, asymmetric, and nonextractable AChE. Individual globular and asymmetric forms then were analyzed by velocity sedimentation on sucrose gradients. The fractions in which external enzyme had been isolated as diethylphosphorylated $\mathrm{AChE}$ were reactivated with 1-methyl2-hydroxyiminomethylpyridinium prior to analysis. Our data indicate that intracellular and external $\mathrm{AChE}$ have different compositions. Intracellular AChE is $79 \%$ globular forms (20\% $10 \mathrm{~S}$ and $59 \% 4$ $\mathrm{S}), 17 \%$ asymmetric forms $(6 \% 16 \mathrm{~S}, 5 \% 12.5 \mathrm{~S}$, and $7 \%$ other), and $4 \%$ nonextractable enzyme. External AChE is 55\% globular forms (26\% $10 \mathrm{~S}$ and $29 \% 4 \mathrm{~S}), 32 \%$ asymmetric forms $(12 \% 16 \mathrm{~S}, 10 \%$ $12.5 \mathrm{~S}$, and $10 \%$ other), and $13 \%$ nonextractable enzyme; therefore external enzyme is composed of relatively more $10 \mathrm{~S}, 16 \mathrm{~S}, 12.5 \mathrm{~S}$, and nonextractable AChE and relatively less $4 \mathrm{~S}$ AChE. The most striking finding to emerge from this study is that the globular and asymmetric forms are all predominantly intracellular in cultured embryonic rat myotubes. Our results indicate that $85 \%$ of the $4 \mathrm{~S}, 69 \%$ of the $10 \mathrm{~S}, 59 \%$ of the $16 \mathrm{~S}$, and $56 \%$ of the $12.5 \mathrm{~S}$ forms are intracellular. These results support the hypothesis that the $10 \mathrm{~S}$ and asymmetric forms of $\mathrm{AChE}$ are assembled intracellularly from $4 \mathrm{~S}$ precursors.
\end{abstract}

The enzyme acetylcholinesterase (AChE) occurs in a number of molecular forms. Three of these forms are globular proteins and three are asymmetric. The globular forms are monomers, dimers, and tetramers of the basic catalytic subunit designated $\mathrm{G}_{1}, \mathrm{G}_{2}$, and $\mathrm{G}_{4}$ (Bon et al., 1979; Vigny et al., 1979). The structure of the asymmetric forms has been analyzed most carefully using $\mathrm{AChE}$

\footnotetext{
${ }^{1}$ We wish to thank Dr. T. L. Rosenberry for his advice throughout this study and for his comments on the manuscript. This investigation was supported by National Institutes of Health Grants NS 15219 and 16577, by National Institutes of Health Medical Scientist Training Grant GM-07250 (S. K. B.), and by a grant from the Muscular Dystrophy Association.

${ }^{2}$ To whom correspondence should be addressed at Department of Pharmacology, Case Western Reserve University School of Medicine, Cleveland, $\mathrm{OH} 44106$.
}

isolated from the electric organ of the eel Electrophorus electricus. 'The three asymmetric forms are designated $A_{4}, A_{8}$, and $A_{12}$ (Bon et al., 1979) and consist of one, two, or three tetrameric assemblies of identical catalytic subunits attached to an elongated collagen-like tail (Bon et al., 1976; Rosenberry and Richardson, 1977; Anglister and Silman, 1978).

In adult rat skeletal muscle, there are major forms of $\mathrm{AChE}$ that sediment at $16 \mathrm{~S}\left(\mathrm{~A}_{12}\right), 10 \mathrm{~S}\left(\mathrm{G}_{4}\right)$, and $4 \mathrm{~S}$ $\left(\mathrm{G}_{1}\right)$, appreciable enzyme that sediments at $12.5 \mathrm{~S}\left(\mathrm{~A}_{8}\right)$, and a minor form that sediments at $6.5 \mathrm{~S}\left(\mathrm{G}_{2}\right)$ (Hall, 1973; Vigny et al., 1976; Carson et al., 1979; Bon et al., 1979; Younkin et al., 1982). In a recent study of the adult rat diaphragm, we discovered (Younkin et al., 1982) that $30 \%$ of the asymmetric forms and $34 \%$ of the $10 \mathrm{~S} \mathrm{AChE}$ are intracellular. These findings led us to propose that 
the asymmetric and $10 \mathrm{~S}$ forms are assembled intracellularly.

In this study, we examined the cellular localization of the forms of $\mathrm{AChE}$ in cultured myotubes derived from the leg musculature of 20-day rat embryos. In these cultures, myotubes begin to form on the 3rd day, are fibrillating vigorously by the 6th day, and by the 8th day, contain all of the forms of AChE present in the adult (Rieger et al., 1980). To evaluate the distribution of the various forms of $\mathrm{AChE}$ in the intracellular and external compartments of the 8-day myotubes, we first inactivated irreversibly either the intracellular or external AChE. We next isolated globular, asymmetric, and nonextractable AChE using a sequential extraction procedure developed previously in this laboratory (Younkin et al. 1982 ) and then separated individual globular and asymmetric forms by velocity sedimentation on sucrose gradients. Our results indicate that large percentages of the $16 \mathrm{~S}(59 \%)$, total asymmetric $(60 \%)$, and $10 \mathrm{~S}(69 \%)$ forms are intracellular in cultured embryonic rat myotubes. These findings strongly support the hypothesis that the asymmetric and $10 \mathrm{~S}$ forms in rat skeletal muscle are assembled intracellularly.

\section{Materials and Methods}

Myotube culture. Cultures were prepared from the leg musculature of 20-day rat fetuses (Zivic-Miller Co., Allison Park, PA). Pregnant female rats were anesthetized with ether and the fetuses were removed using an aseptic technique. Skinned hindlimbs then were separated from each fetus at midthigh and the feet were removed. Dissected legs were stored al $0^{\circ} \mathrm{C}$ in Hanks' balanced salt solution without calcium or magnesium until all dissection was complete. After dissection, each leg was rinsed in Hanks' balanced salt solution and cut into six to eight pieces with scissors. These pieces were pooled, about 25 $\mathrm{ml}$ of $0.05 \%$ collagenase in Puck's balanced salt solution $\left(0.137 \mathrm{~m} \mathrm{NaCl}, 5.4 \mathrm{~mm} \mathrm{KCl}, 1.1 \mathrm{~mm} \mathrm{KH} \mathrm{KO}_{4}, 2.0 \mathrm{~mm}\right.$ $\mathrm{Na}_{2} \mathrm{HPO}_{4}, 0.11 \mathrm{~mm} \mathrm{CaCl}, 0.06 \mathrm{~mm} \mathrm{MgSO}_{4}, \mathrm{pH} 7.4$ ) were added, and the preparation was incubated at $37^{\circ} \mathrm{C}$ for 30 $\mathrm{min}$. Prior to incubation and at 15 and $30 \mathrm{~min}$, the tissue was aspirated mechanically by pipette for 1 to $2 \mathrm{~min}$ to facilitate dissociation. After dissociation, the cells were filtered through gauze, and the filtrate was supplemented with $20 \mathrm{ml}$ of culture medium (Dulbecco's modified Eagle's medium containing $10 \%$ fetal calf serum, 50 units/ $\mathrm{ml}$ of penicillin, and $50 \mu \mathrm{g} / \mathrm{ml}$ of streptomycin) and centrifuged at $500 \times g$ for $5 \mathrm{~min}$. The cells then were resuspended in culture medium at a density of about 670,000 cells $/ \mathrm{ml}$, and 3-ml aliquots were seeded into 60 mm tissue culture dishes (Falcon) coated with $1 \%$ gelatin. Each fetus yielded about three cultures $(9 \mathrm{ml})$. Cultures were maintained at $37^{\circ} \mathrm{C}$ in an atmosphere of $10 \% \mathrm{CO}_{2}$ and $90 \%$ air. Medium was changed on day 4, and myotubes were harvested on day 8.

Sequential extraction of globular, asymmetric, and nonextractable AChE. Extraction was carried out using a modification of the method described by Younkin et al. (1982). Globular forms of AChE were extracted initially (S1) from washed cells using low ionic strength buffer (LIB)-a $10 \mathrm{mM}, \mathrm{pH} \mathrm{7,} \mathrm{phosphate} \mathrm{buffer} \mathrm{containing} 1 \%$ Triton X-100, $5 \mathrm{~mm} N$-ethylmaleimide, $2 \mathrm{~mm}$ benzamidine, and $10 \mathrm{~mm}$ EGTA. The pellet remaining after the initial extraction was extracted twice with LIB to remove residual globular forms (S2 and S3). Asymmetric forms (S4) and residual asymmetric forms (S5) then were obtained by extracting twice with high ionic strength buffer (HIB), a buffer identical to LIB except that it contained additionally $1.0 \mathrm{M} \mathrm{NaCl}$. The pellet remaining after these five extractions was homogenized in HIB, and the homogenate (H6) was assayed to evaluate the $\mathrm{AChE}$ that was not extracted. Comparison of the activity of the initial homogenate with the sum of the activities of the six fractions showed that $92 \pm 4 \%$ of total AChE activity was recovered $(n=12)$. $N$-Ethylmaleimide, benzamidine, and EGTA were included in both extraction buffers to inhibit proteolytic degradation of AChE (Younkin et al. 1982). All homogenizations were carried out in $1.25 \mathrm{ml}$ of buffer using a Polytron (Brinkmann) equipped with a Kinematica generator run at a setting of 8 for $10 \mathrm{sec}$. To improve recovery, residual homogenate was washed from the Polytron by operating it for 5 sec at the same speed using a fresh $1.25-\mathrm{ml}$ volume of buffer. The original homogenate and the wash were pooled prior to centrifugation to give $2.5 \mathrm{ml}$ of final homogenate. The Polytron was cleaned between homogenizations by operating it at the same setting for $5 \mathrm{sec}$ in at least $800 \mathrm{ml}$ of distilled water. All five centrifugations were carried out for $30 \mathrm{~min}$ at $39,000 \times g$ in a Sorvall centrifuge equipped with an SS/34 rotor.

Separation of individual forms on sucrose gradients. Samples $(0.20 \mathrm{ml})$ were applied to 5 to $25 \%$ (w:w) isokinetic sucrose gradients (McCarty et al., 1974) which contained $10 \mathrm{mM}$ phosphate buffer, $\mathrm{pH} 7,1.0 \mathrm{M} \mathrm{NaCl}, 0.1$ mM tetraisopropyl pyrophosphoramide (iso-OMPA), and $1 \%$ Triton X-100. Gradients were formed in Beckman cellulose nitrate tubes (No. 331370) filled to within $8 \mathrm{~mm}$ from the top. Centrifugation was carried out at $4^{\circ} \mathrm{C}$ in a Beckman L8-70 ultracentrifuge using an SW41-Ti rotor (Beckman) operated at $40,000 \mathrm{rpm}$ until $w^{2} t=10^{12}$. Gradients were fractionated directly into minivials (10drop, 0.2-ml fractions) and were assayed without dilution. Svedberg constants were calculated as previously described (Younkin et al., 1982) using catalase (11.4 S) as a standard. Comparison of the AChE in innervated adult rat diaphragm with enzyme obtained from cultured embryonic rat myotubes in an experiment in which matched gradients were run simultaneously showed that the major forms of AChE in each preparation had essentially identical sedimentation coefficients of $16 \mathrm{~S}, 12.5 \mathrm{~S}, 10 \mathrm{~S}$, and $4 \mathrm{~S}$. AChE recovery was evaluated by comparing the AChE activity applied with the summed activities of the gradient fractions and was 50 to $90 \%$.

$A C h E$ assay. AChE was assayed using a modification (Younkin et al., 1982) of the radiometric assay developed by Johnson and Russell (1975). Assays were carried out in minivials (No. 58-536, Sarstedt) by adding $50 \mu \mathrm{l}$ of 3 $\times 10^{-4}$ м $\left[{ }^{3} \mathrm{H}\right]$ acetylcholine to $200-\mu \mathrm{l}$ samples. Gradient fractions had a volume of about $200 \mu \mathrm{l}$ and were assayed without dilution; extracts and homogenates were diluted $1: 10$ so that the final assay mixture contained $0.2 \%$ Triton $\mathrm{X}-100,1.0 \mathrm{~mm} N$-ethylmaleimide, $0.4 \mathrm{~mm}$ benzamidine, $2 \mathrm{~mm}$ EGTA, $0.1 \mathrm{~mm}$ iso-OMPA, $100 \mathrm{~mm} \mathrm{NaCl}$, and 10 mM sodium phosphate buffer, $\mathrm{pH} 7$.

Washing procedure. To remove the various inhibitors described below, myotubes were immersed in at least 500 
$\mathrm{ml}$ of phosphate-buffered saline (PBS; $137 \mathrm{~mm} \mathrm{NaCl}, 5.4$ mM KCl, $1.1 \mathrm{~mm} \mathrm{KH} \mathrm{KO}_{4}, 2.0 \mathrm{~mm} \mathrm{Na} \mathrm{HPO}_{4}, \mathrm{pH} 7.2$ ), and the $500 \mathrm{ml}$ of PBS were replaced twice.

Inactivation of external AChE with echothiophate. PBS containing $1.0 \mu \mathrm{M}$ echothiophate iodide was added to washed myotube cultures at $2^{\circ} \mathrm{C}$. At various times thereafter, echothiophate was washed from the myotubes with PBS, and homogenates or extracts were prepared. Assays were carried out before and after reactivating the inactivated (diethylphosphorylated) external enzyme by exposing it to $0.2 \mathrm{~mm}$ 1-methyl-2-hydroxyiminomethylpyridinium (2-PAM) for $45 \mathrm{~min}$ at room temperature as previously described by Younkin et al. (1982). To confirm that 2-PAM treatment completely reactivates diethylphosphorylated enzyme, homogenates of echothiophatetreated myotubes were 2-PAM-reactivated and compared with homogenates of matched control myotubes. In 5 experiments, the activity of the 2-PAM-reactivated echothiophate-treated myotubes was $106 \pm 7 \%$ of the activity of matched controls.

Inactivation of external AChE with methanesulfonyl fluoride (MSF) in the presence of decamethonium. PBS containing $10 \mu \mathrm{M} \mathrm{MSF}$ and $100 \mu \mathrm{M}$ decamethonium bromide was added to washed myotube cultures at $2^{\circ} \mathrm{C}$. At various times thereafter, the MSF/decamethonium solution was washed from the cells with PBS. Homogenates or extracts then were prepared and assayed for AChE activity.

External AChE assay. External AChE was assayed using a modification of the technique developed by Rotundo and Fambrough (1980) to measure cell surface AChE in embryonic chick myotubes. Myotubes were washed with PBS and kept at $2^{\circ} \mathrm{C}$. Cells from three dishes were pooled (cells can be removed from the dishes in one unbroken sheet). $\left[{ }^{3} \mathrm{H}\right]$ Acetylcholine $(0.75 \mathrm{~mm}$, 1:100 labeled:unlabeled) in PBS then was added. The reaction vessels were agitated gently with a Gyrotary Shaker model G2 (New Brunswick Scientific) at $100 \mathrm{rpm}$. To measure the activity of the external enzyme, $0.25-\mathrm{ml}$ aliquots were removed at various times, the amount of $\left[{ }^{3} \mathrm{H}\right]$ acetate present was measured as described by Younkin et al. (1982), and the rate of hydrolysis of acetylcholine was determined after correcting for the volumes removed by sampling. At the end of $1 \mathrm{hr}$, a volume of $\left[{ }^{3} \mathrm{H}\right]$ acetylcholine solution with $2 \%$ Triton X-100 equal to that remaining in the vessels was added, and the cells were aspirated through Pasteur pipettes for 60 to $90 \mathrm{sec}$ to solubilize the $\mathrm{AChE}$ in the myotubes. Aliquots $(0.25$ $\mathrm{ml}$ ) then were removed at various times and processed as described above to measure total AChE activity.

Isolation of intracellular and external AChE. To obtain a preparation in which only intracellular AChE was active, the external enzyme was inactivated by exposing cultures at $2^{\circ} \mathrm{C}$ to $10 \mu \mathrm{M} \mathrm{MSF}$ and $100 \mu \mathrm{M}$ decamethonium for $1 \mathrm{hr}$. To obtain a preparation in which only external enzyme was active, myotubes were treated with $1 \mu \mathrm{M}$ echothiophate for $15 \mathrm{~min}$ at $2^{\circ} \mathrm{C}$ to protect (diethylphosphorylate) external AChE, washed to remove echothiophate, treated with $1 \mathrm{~mm} \mathrm{MSF}$ at $37^{\circ} \mathrm{C}$ for $30 \mathrm{~min}$ to inactivate intracellular $\mathrm{AChE}$ irreversibly, and washed to remove MSF. After sequential extraction, fractions containing isolated (diethylphosphorylated) external AChE were reactivated with 2-PAM as described above. Control experiments, in which cultures treated only with $1 \mathrm{~mm} \mathrm{MSF}$ at $37^{\circ} \mathrm{C}$ for 30 min were extracted sequentially and treated with 2-PAM, established that this MSF treatment inactivates essentially all intracellular enzyme and that sulfonylated enzyme is not reactivated by 2 -PAM.

In our isolation procedures, we inactivated intracellular or external AChE selectively by sulfonylation with MSF rather than by diethylphosphorylation with echothiophate because sulfonylated enzyme reactivates more slowly than diethylphosphorylated enzyme. This was particularly important in this study because of the overnight centrifugation necessary to separate individual forms on sucrose gradients and the long assay times required to evaluate the gradient profiles of the asymmetric forms. Appropriate control experiments established that sulfonylated enzyme does not reactivate measurably under the conditions of our analysis.

Quantitation of AChE activity. The sequential extraction data on whole myotube $\mathrm{AChE}$ and on isolated intracellular and external enzyme were used to calculate the amounts of globular (S1 + S2 + S3), asymmetric ( $\mathrm{S} 4+$ S5), and nonextractable AChE in each pool. The percentages of globular, asymmetric, and nonextractable enzyme in each pool were calculated using the summed activity in the six fractions as total AChE. The relative activity of each form on a gradient was obtained by expressing the activity in each fraction as a percentage of the total activity in the gradient and summing the percentages, from minimum to minimum, in each of the peaks corresponding to particular forms. To calculate the contribution of each form to a particular pool, the percentage per 100 of the individual globular or asymmetric form on the gradient was multiplied by the percentage of the total globular or asymmetric enzyme in the pool.

Materials. Dulbecco's modified Eagle's medium and fetal calf serum were from Flow Laboratories, Hank's balanced salt solution and antibiotics were from M. A. Bioproducts, collagenase (CLS II) was from Worthington, $\left[{ }^{3} \mathrm{H}\right]$ acetylcholine was from New England Nuclear, echothiophate iodide was from Ayerst, methanesulfonyl fluoride (MSF) and $N$-ethylamaleimide were from Eastman, and 2-PAM, decamethonium bromide, catalase, sucrose (grade 1), tetraisopropyl pyrophosphoramide (iso-OMPA), benzamidine, EGTA, and Triton X-100 were from Sigma.

\section{Results}

The experimental results described below were obtained using 8-day cultures of myotubes derived from 20day rat embryos. The myotubes in these cultures developed as described in earlier studies (Heinemann et al., 1977; Koenig and Vigny, 1978; Bloch, 1979; Rieger et al., 1980). Myoblasts started fusing to form myotubes in 3 days, the myotubes began to fibrillate in 5 days, and, in 6 days, virtually all myotubes were fibrillating vigorously. The cells other than myotubes in these cultures appeared to be mostly fibroblasts which have been reported to have little, if any, AChE activity (Wilson et al., 1973; Fluck and Strohman, 1973; Koenig and Vigny, 1978; Rotundo and Fambrough, 1979).

Quantitation of external and intracellular AChE in cultured rat myotubes. The relative amounts of AChE in 
the intracellular and external compartments of cultured rat myotubes were determined by three different methods. In the first method, we used echothiophate, a cationic phosphorylating agent, to inactivate external AChE selectively. Figure 1 shows the time course of enzyme inactivation when $1.0 \mu \mathrm{M}$ echothiophate was added to myotubes at $2^{\circ} \mathrm{C}$. Within $2 \mathrm{~min}$, about onefourth of the cellular enzyme was inactivated, and there was no additional inactivation over the next $38 \mathrm{~min}$. We interpret the pool of $\mathrm{AChE}$ that was inactivated rapidly to be external enzyme and the pool that was resistant to inactivation to be intracellular enzyme. In 10 experiments, we exposed cultures at $2^{\circ} \mathrm{C}$ to $1.0 \mu \mathrm{M}$ echothiophate for $15 \mathrm{~min}$, assayed the residual (intracellular) activity, reactivated the inactivated (external) enzyme with 2-PAM, and measured total activity. In these experiments $73.1 \pm 2.5 \%$ of the $\mathrm{AChE}$ was active after exposure to echothiophate (intracellular) and $26.9 \pm 2.5 \%$ was inactivated by echothiophate (external).

In the second method, we used MSF in the presence of decamethonium to inactivate external enzyme selectively. Decamethonium penetrates membranes very slowly and, at a concentration of $100 \mu \mathrm{M}$, accelerates the inactivation of AChE by MSF approximately 30-fold (Pavlic and Wilson, 1978). Figure 2 shows the time course of enzyme inactivation when $10 \mu \mathrm{M}$ MSF in the presence of $100 \mu \mathrm{M}$ decamethonium bromide was added to myotubes at $2^{\circ} \mathrm{C}$. The time course of inactivation was similar, though not identical, to that seen with echothio-

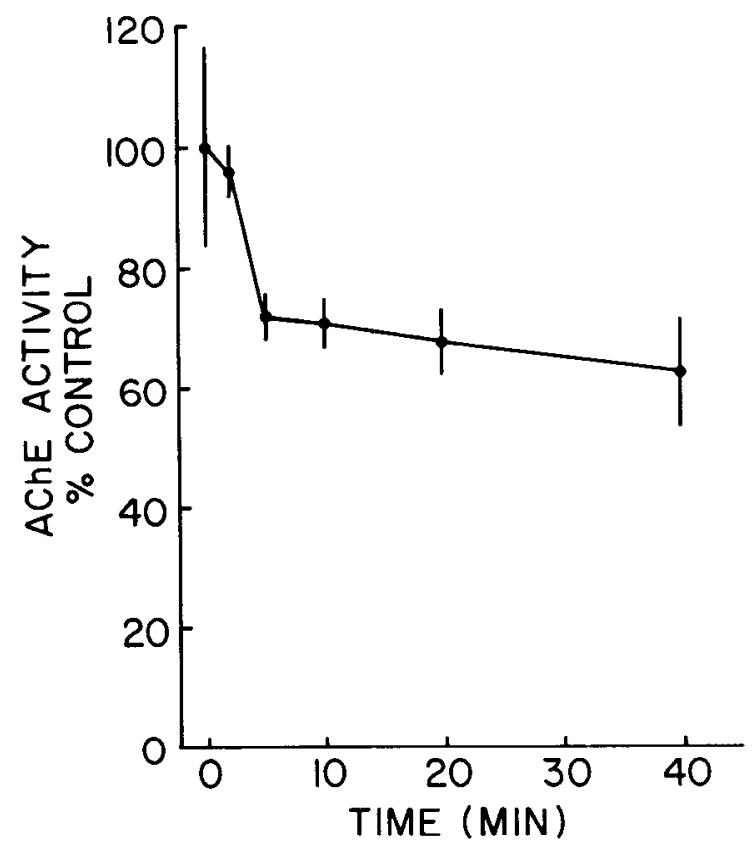

Figure 1. Time course of echothiophate inactivation of $\mathrm{AChE}$ in rat myotube cultures. Myotubes at $2^{\circ} \mathrm{C}$ were exposed to 1.0 $\mu \mathrm{M}$ echothiophate in phosphate-buffered saline for various times. They then were washed three times with phosphatebuffered saline and homogenized in low ionic strength buffer. AChE activity in the homogenates was assayed both before and after reactivation of diethylphosphorylated enzyme with 2PAM. The values plotted represent the activity present before treatment with 2-PAM as a percentage of the activity present after reactivation of the enzyme. The percentages shown are the mean \pm SEM of 3 to 7 determinations.

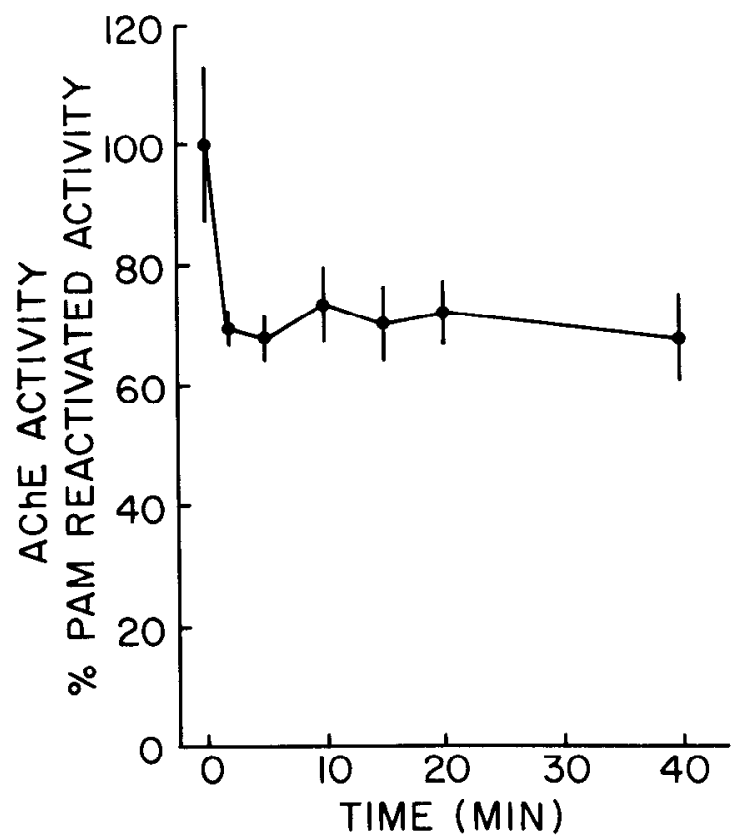

Figure 2. Time course of methanesulfonyl fluoride (MSF) inactivation of $\mathrm{AChE}$ in rat myotube cultures. Myotubes at $2^{\circ} \mathrm{C}$ were exposed to $10 \mu \mathrm{M} \mathrm{MSF}$ and $100 \mu \mathrm{M}$ decamethonium in phosphate-buffered saline for various times. they then were washed three times with phosphate-buffered saline and homogenized in low ionic strength buffer. Homogenates were assayed for AChE activity. The values plotted represent the activity present in MSF-treated cultures as a percentage of the activity in matched control cultures. The percentages shown are the mean \pm SEM of 3 to 14 determinations.

phate. About one-fourth of the enzyme was inactivated within $5 \mathrm{~min}$, and the remaining enzyme was inactivated very slowly. Extrapolation of the slow component of inactivation to zero time indicates that $73.7 \%$ of the enzyme in myotubes was intracellular and $26.3 \%$ was external.

The third method used to quantitate external and intracellular $\mathrm{AChF}$ was a modification of the technique developed by Rotundo and Fambrough (1980) to measure external AChE in chick myotubes. In these experiments, $\left[{ }^{3} \mathrm{H}\right]$ acetylcholine was added to intact myotubes at $2^{\circ} \mathrm{C}$ and a rate of hydrolysis was determined. Triton X-100 then was added to solubilize the myotubes, and the rate of hydrolysis was redetermined. At $2^{\circ} \mathrm{C}$, acetylcholine does not enter myotubes (Rotundo and Fambrough, 1980); therefore the two rates measured are representative of external and total cellular AChE activity. As an additional control, we inactivated external enzyme with echothiophate as described above and measured hydrolysis rates before and after solubilization with Triton X100. Typical results from an experiment of this type are shown in Figure 3. In 3 experiments, the activity of the external enzyme in intact cells was $25.3 \pm 3.2 \%$ of the total activity in solubilized myotubes. In each experiment, pretreatment with echothiophate virtually abolished the activity of the external enzyme in intact myotubes, and the activity of the intracellular enzyme in echothiophate-treated cells (measured after solubilization) agreed well with the difference between the total and external activities in normal myotubes. 
The results obtained with the three different methods used to quantitate external and intracellular enzyme are summarized in Table I. It is evident that the agreement among these methods is excellent. The mean values obtained are $73.8 \pm 0.5 \%$ for intracellular enzyme and $26.2 \pm 0.5 \%$ for external enzyme.

Molecular forms of AChE in cultured rat myotubes. Myotubes were subjected to a sequential homogenization procedure similar to that described by Younkin et al.

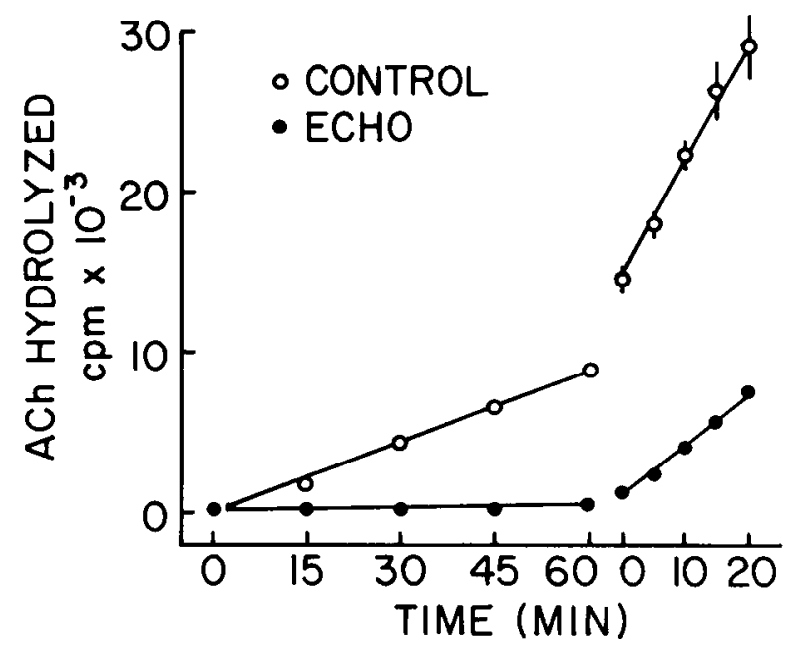

Figure 3. External AChE assay. Myotube cultures were washed with phosphate-buffered saline, and the cells from three dishes $(60 \mathrm{~mm})$ were pooled. To measure external AChE activity, myotubes at $2^{\circ} \mathrm{C}$ were exposed to $\left[{ }^{3} \mathrm{H}\right]$ acetylcholine and, at various times, aliquots were removed and $\left[{ }^{3} \mathrm{H}\right]$ acetate was measured. At the end of $1 \mathrm{hr}$, the AChE in the myotubes was solubilized by adding Triton X-100 (final concentration, $1 \%$ ). Total AChE activity then was measured by again removing aliquots at various times and measuring $\left[{ }^{3} \mathrm{H}\right]$ acetate. The open circles represent the amount of $\left[{ }^{3} \mathrm{H}\right]$ acetylcholine hydrolyzed by control cultures; the solid circles represent the amount hydrolyzed by cultures pretreated with $1 \mu \mathrm{M}$ echothiophate for $15 \mathrm{~min}$ at $2^{\circ} \mathrm{C}$. Each point is the mean \pm SEM of three determinations. Where no error bar is shown, the error is less than the size of the circles.

\section{TABLE I}

Comparison of the methods used to evaluate the percentage of intracellular and external AChE in cultured embryonic rat myotubes

The data are based on 8-day cultures derived from 20-day rat embryos. Method I was repeated 10 times, method II is based on the data shown in Figure 2, and method III was repeated 3 times. The percentages shown for methods I and III are the mean \pm SEM.

\begin{tabular}{c} 
Method \\
\hline Intracellular
\end{tabular}

I. Exposure of cultures at $2^{\circ} \mathrm{C}$ to 1.0 $\mu \mathrm{M}$ echothiophate for $15 \mathrm{~min}$

II. Exposure of cultures at $2^{\circ} \mathrm{C}$ to $10 \mu \mathrm{M}$ $\mathrm{MSF}+100 \mu \mathrm{M}$ decamethonium and

extrapolation to zero time of the slow component of inhibition

III. Relative rates of hydrolysis of $\mathrm{ACh}$ at $2^{\circ} \mathrm{C}$ by myotube cultures before and after solubilization with $1 \%$ Triton $\mathrm{X}-100$

Mean \pm SEM of three methods

\section{$73.1 \pm 2.5 \quad 26.9 \pm 2.5$}

$73.7 \quad 26.3$

$74.7 \pm 3.2 \quad 25.3 \pm 3.2$
(1982) to isolate globular, asymmetric, and nonextractable AChE. Globular forms of AChE were solubilized quantitatively by extracting three times with low ionic strength buffer ( $\mathrm{S} 1, \mathrm{~S} 2$, and $\mathrm{S} 3$ ). Asymmetric forms then were solubilized by extracting twice with high ionic strength buffer (S4 and S5). A small amount of nonextractable enzyme was present in the homogenate $(\mathrm{H} 6)$ of the final pellet. Quantitative data on the AChE activities of the six fractions obtained with this procedure are shown in Table II.

Figure $4 A$ shows a typical sucrose gradient profile of the AChE solubilized in low ionic strength buffer (S1). There are two major forms with sedimentation coefficients of $4 \mathrm{~S}$ and $10 \mathrm{~S}$ that correspond to the $\mathrm{G}_{1}$ and $\mathrm{G}_{4}$ forms in bovine superior cervical ganglion (Vigny et al., 1979) and adult skeletal muscle (Hall, 1973; Vigny et al., 1976; Carson et al., 1979; Bon et al., 1979; Younkin et al., 1982). It is evident from Figure $4 A$ that low ionic strength buffer solubilizes only globular forms of $\mathrm{AChE}$; forms with the sedimentation coefficients characteristic of asymmetric forms are not present.

Figure $5 A$ shows a typical sucrose gradient profile of the AChE solubilized in high ionic strength buffer (S4). Most of this enzyme has sedimentation coefficients of 16 $\mathrm{S}$ and $12.5 \mathrm{~S}$ that correspond to the $\mathrm{A}_{12}$ and $\mathrm{A}_{8}$ forms in bovine superior ganglion (Vigny et al., 1979) and adult rat skeletal muscle (Carson et al., 1979; Bon et al., 1979; Younkin et al., 1982). There is, however, appreciable enzyme that sediments more slowly and has a sedimentation coefficient of about $10 \mathrm{~S}$. Table II shows that the activity in the third low ionic strength extract (S3) was only $11 \%$ of the activity in the initial high ionic strength extract (S4). The slowly sedimenting enzyme constituted considerably more than $11 \%$ of the AChE in $\mathrm{S} 4$ (Fig. $5 \mathrm{~A}$; Table III); therefore, it is clear that the slowly sedimenting enzyme was extracted preferentially in high ionic strength buffer. The slowly sedimenting enzyme in S4 could be either an unusual form belonging to the asymmetric class or $10 \mathrm{~S}$ globular enzyme that, for some reason, requires high ionic strength buffer for solubilization. Asymmetric forms of AChE aggregate in low ionic strength buffer, whereas globular forms do not (Bon et al., 1979); thus, experiments were performed to determine if the slowly sedimenting enzyme in $\mathrm{S} 4$ aggregates in low ionic strength buffer. Figure 6 shows the results of experiments in which we compared the gradient profiles of S4

TABLE II

Sequential extraction of globular, asymmetric, and nonextractable AChE from cultured embryonic rat myotubes

Sequential extraction was carried out with low ionic strength buffer (LIB) and high ionic strength buffer (HIB) as described under "Materials and Methods". 'The data are based on 8-day cultures derived from 20-day rat embryos. AChE activity is expressed as picomoles of acetylcholine hydrolyzed per min per dish of myotubes. The activities shown are the mean \pm SEM of six determinations.

\begin{tabular}{cclc}
\hline Fraction & Buffer & \multicolumn{1}{c}{ Forms } & AChE Activity \\
\hline S1 & LIB & Globular & $1202 \pm 147$ \\
S2 & LIB & Residual globular & $71 \pm 10$ \\
S3 & LIB & Residual globular & $31 \pm 5$ \\
S4 & HIB & Asymmetric & $290 \pm 4$ \\
S5 & HIB & Residual asymmetric & $32 \pm 5$ \\
H6 & HIB & Nonextractable & $91 \pm 18$ \\
\hline
\end{tabular}




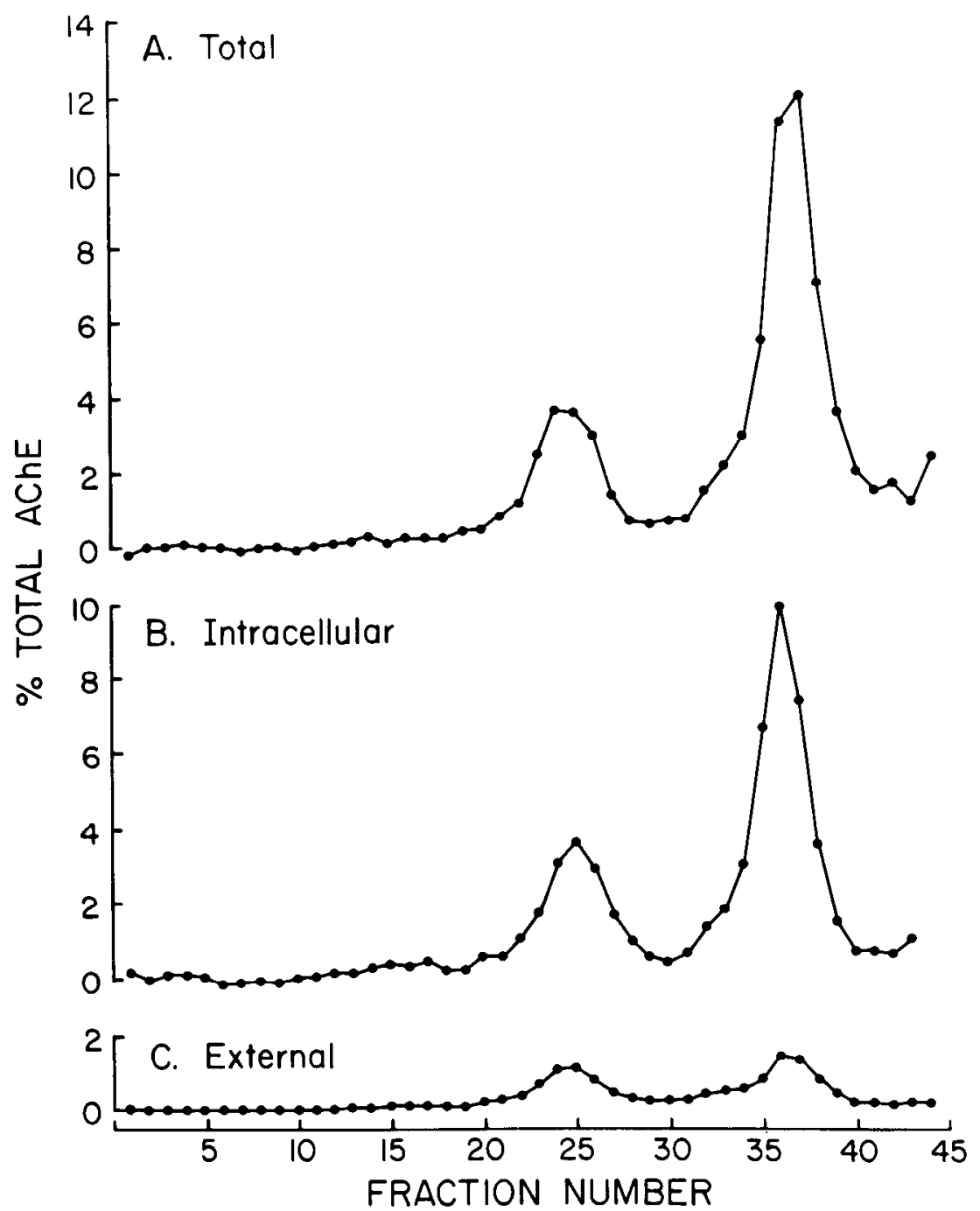

Figure 4. Sucrose gradient profiles of total globular forms and the globular forms in the intracellular and external compartments of cultured rat myotubes. The data in this figure and in Figure 5 were derived from a single experiment in which a large number of identical cultures were initiated simultaneously, and total, intracellular, and external AChE were investigated in parallel. Intracellular and external $\mathrm{AChE}$ were isolated as described in the text. Control myotubes and myotubes in which the intracellular or external AChF had been isolated then were subjected to sequential extraction, and the S1 (globular) and S4 (asymmetric) fractions were analyzed by velocity sedimentation on sucrose gradients. The gradient profiles of total $(A)$, intracellular $(B)$, and external $(C)$ globular forms are shown above. The corresponding profiles of the asymmetric forms are shown in Figure 4. The AChE activity in each gradient fraction is expressed as a percentage of the total activity in the myotubes; therefore, the area under each peak represents the contribution of that component to whole myotube activity. The sedimentation coefficients of the major globular forms are $10 \mathrm{~S}$ (left) and $4 \mathrm{~S}$ (right).

AChE applied to the standard high ionic strength sucrose gradient and of $\mathrm{S} 4 \mathrm{AChE}$ that was dialyzed against low ionic strength buffer $\left(10 \mathrm{mM} \mathrm{PO}_{4}\right.$ buffer, $\mathrm{pH} 7$, containing $1 \%$ Triton X-100, $5 \mathrm{~mm} N$-ethylmaleimide, $2 \mathrm{~mm}$ benzamidine, and $10 \mathrm{mM}$ EGTA) and then applied to a low ionic strength sucrose gradient (identical to the standard gradient except that it lacked $1.0 \mathrm{M} \mathrm{NaCl}$ ). It is evident in Figure 6 that the slowly sedimenting $(\sim 10 \mathrm{~S}) \mathrm{AChE}$ in $\mathrm{S} 4$ aggregated in low ionic strength buffer and therefore sedimented to the bottom of the low ionic strength gradient along with the larger asymmetric forms. In control experiments, we established that the $4 \mathrm{~S}$ and 10 $\mathrm{S}$ forms in the $\mathrm{S} 1$ fraction do not aggregate and sediment to the bottom of low ionic strength gradients. Thus, all forms of $\mathrm{AChE}$ in $\mathrm{S} 4$ share one important property of the "asymmetric" class of AChE forms, the tendency to aggregate in low ionic strength buffer. For this reason, we will refer to the forms of AChE in $\mathrm{S} 4$ collectively as asymmetric enzyme.

Isolation and characterization of intracellular and external $A C h E$. Whole myotube, intracellular, and external AChE were investigated in parallel using identical cultures initiated simultaneously. After isolation of external and intracellular AChE, cultures were subjected to sequential extraction as described above. Individual globular and asymmetric forms then were analyzed by velocity sedimentation on sucrose gradients.

To isolate intracellular AChE, external AChE was inactivated irreversibly by treating myotubes at $2{ }^{\circ} \mathrm{C}$ with $10 \mu \mathrm{M}$ MSF and $100 \mu \mathrm{M}$ decamethonium for $1 \mathrm{hr}$. In isolating intracellular enzyme, it was crucial that the intracellular enzyme be uncontaminated by external en- 


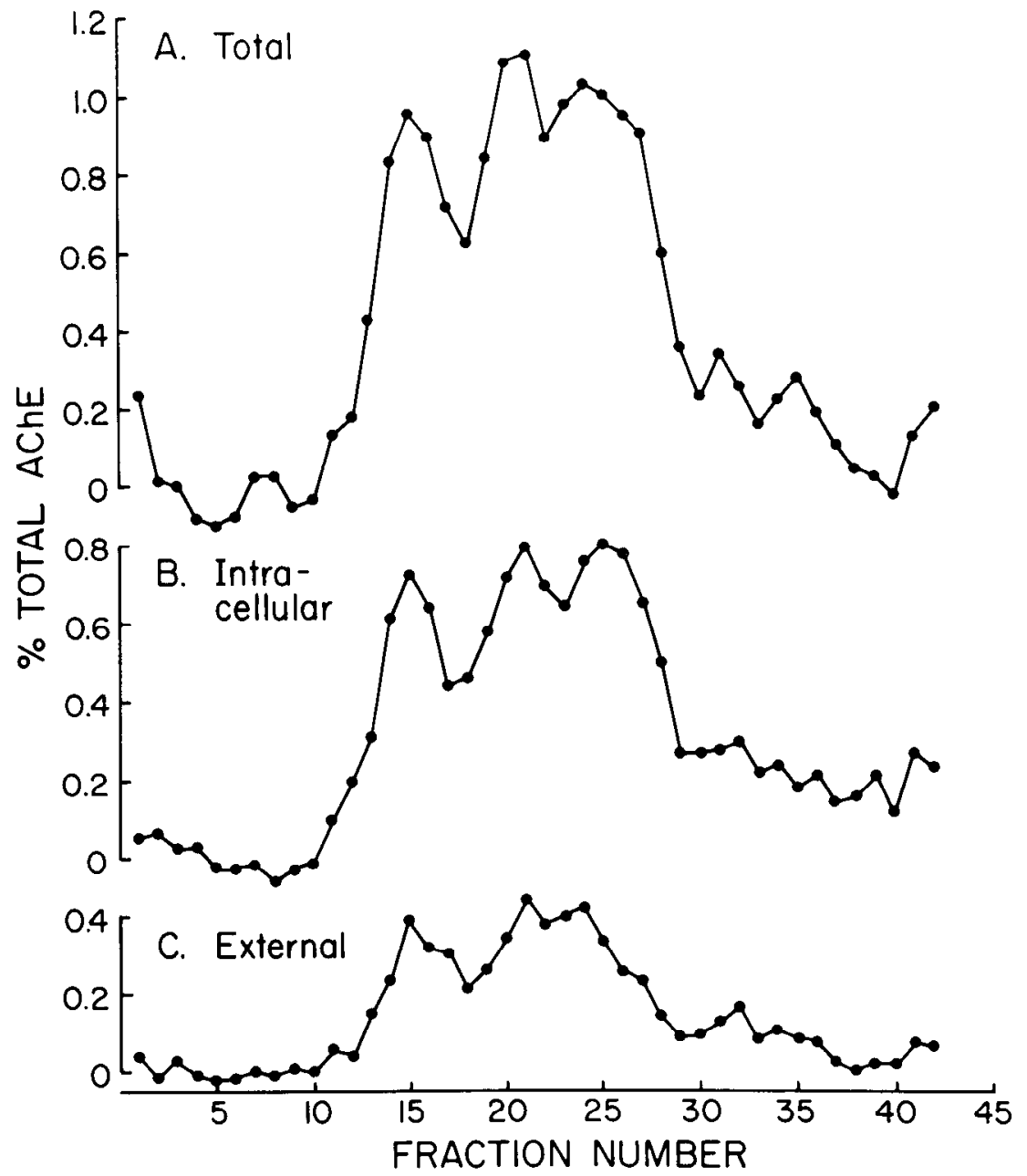

Figure 5. Sucrose gradient profiles of total asymmetric forms and the asymmetric forms in the intracellular and external compartments of cultured rat myotubes. The data in this figure and in Figure 4 were derived from a single experiment in which a large number of identical cultures were initiated simultaneously, and total, intracellular, and external AChE were investigated in parallel. Intracellular and external AChE were isolated as described in the text. Control myotubes and myotubes in which the intracellular or external $\mathrm{AChE}$ had been isolated then were subjected to sequential extraction, and the S1 (globular) and S4 (asymmetric) fractions were analyzed by velocity sedimentation on sucrose gradients. 'The gradient profiles in total ( $A$ ), intracellular $(B)$, and external $(C)$ asymmetric forms are shown above. The corresponding profiles of the globular forms are shown in Figure 4. The AChE activity in each gradient fraction is expressed as a percentage of the total activity in the myotubes; therefore, the area under each peak represents the contribution of that component to whole myotube activity. The sedimentation coefficients of the asymmetric forms are (left to right) $16 \mathrm{~S}, 12.5 \mathrm{~S}$, and approximately $10 \mathrm{~S}$.

TABLE III

Composition of whole myotube, external, and intracellular AChE in cultured embryonic rat myotubes

The relative amounts of the various forms in each pool were determined as described under "Materials and Methods." The data are based on 8-day cultures derived from 20 -day rat embryos. The percentages shown are the mean \pm SEM of three to six measurements.

\begin{tabular}{lrcc}
\hline & Whole Myotube & External & Intracellular \\
\hline \multicolumn{3}{c}{ \% total activity in pool } \\
Globular & $75.4 \pm 1.8$ & $55.2 \pm 2.9$ & $78.7 \pm 1.3$ \\
$10 \mathrm{~S}$ & $21.0 \pm 0.9$ & $25.8 \pm 2.7$ & $20.2 \pm 1.9$ \\
$4 \mathrm{~S}$ & $54.5 \pm 1.5$ & $29.4 \pm 2.8$ & $58.5 \pm 2.1$ \\
& & & \\
Asymmetric & $18.4 \pm 1.2$ & $31.7 \pm 3.2$ & $17.2 \pm 1.0$ \\
$\quad$ 16 S & $5.8 \pm 0.5$ & $11.5 \pm 2.0$ & $5.8 \pm 0.7$ \\
12.5 S & $5.7 \pm 0.6$ & $10.2 \pm 2.3$ & $4.8 \pm 0.5$ \\
Other & $6.9 \pm 0.6$ & $9.9 \pm 2.8$ & $6.6 \pm 0.8$ \\
& & & \\
Nonextractable & $6.2 \pm 1.8$ & $13.1 \pm 3.2$ & $4.1 \pm 1.0$ \\
& & & 100.0 \\
Total & 100.0 & 100.0 &
\end{tabular}

zyme and less important that the recovery of intracellular enzyme be quantitative. It was for this reason that we inactivated external enzyme for $1 \mathrm{hr}$.

To isolate external AChE, myotubes at $2^{\circ} \mathrm{C}$ were exposed to $1.0 \mu \mathrm{M}$ echothiophate for $15 \mathrm{~min}$ to protect external AChE, washed to remove echothiophate, treated with $1.0 \mathrm{mM} \mathrm{MSF}$ for $30 \mathrm{~min}$ at $37^{\circ} \mathrm{C}$ to inactivate intracellular AChE irreversibly, and washed to remove MSF. In isolating external AChE, it was important to establish that all intracellular enzyme was inactivated by MSF and that 2-PAM reactivated only diethylphosphorylated (external) enzyme and not sulfonylated (intracellular) enzyme. We routinely assayed all fractions obtained by sequential extraction (whole myotube, isolated intracellular, and isolated external fractions) before and after treatment with 2-PAM. Analysis of the isolated intracellular fractions (in which external AChE is sulfonylated) showed that 2-PAM does not reactivate sulfonylated enzyme. Prior to 2-PAM reactivation, isolated external fractions contain external AChE that is diethyl- 


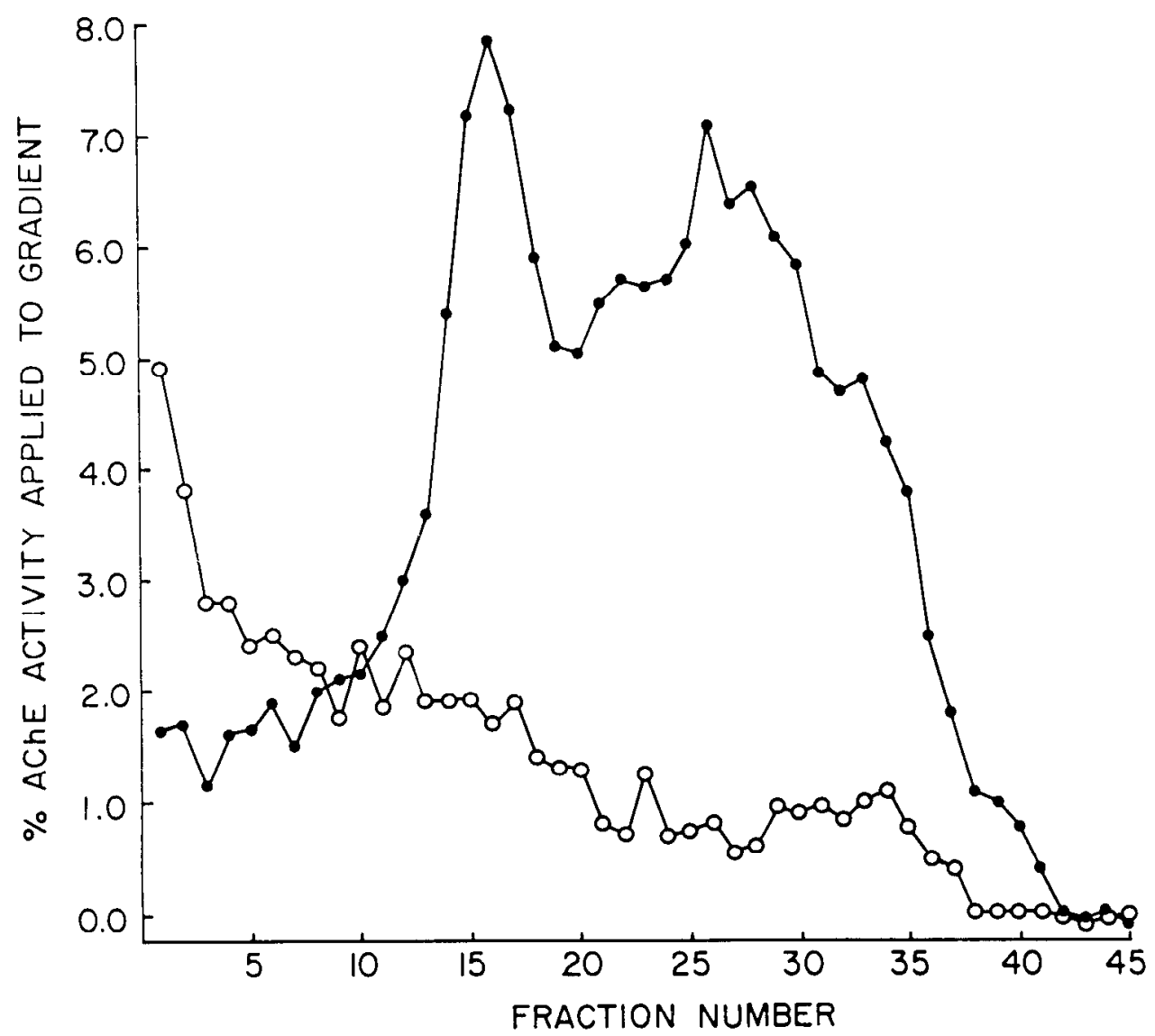

Figure 6. Sucrose gradient profiles of the $\mathrm{S} 4$ fraction after application to high ionic strength and low ionic strength sucrose gradients. The cells in three $100-\mathrm{mm}$ culture dishes were pooled and subjected to sequential extraction as described under "Materials and Methods." The initial high ionic strength extract (S4) that was obtained was divided into two parts. One part was applied to a standard high ionic strength sucrose gradient (O). The other part was dialyzed against low ionic strength buffer and then applied to a low ionic strength sucrose gradient that was identical to the standard gradient except that it lacked $1.0 \mathrm{M} \mathrm{NaCl}$ (O). The sedimentation coefficients of the asymmetric forms on the standard high ionic strength gradient are (left to right) $16 \mathrm{~S}$, $12.5 \mathrm{~S}$, and approximately $10 \mathrm{~S}$. Note that the activity in each fraction is expressed as a percentage of the activity applied to the gradient.

phosphorylated and intracellular enzyme that is sulfonylated. Analysis of these fractions showed that they had less than $3 \%$ of the activity of control myotubes; thus, intracellular $\mathrm{AChE}$ was almost entirely inactivated by the MSF treatment employed.

The results of a single large experiment, in which we initiated a large number of identical cultures simultaneously and investigated whole myotube, intracellular, and external enzyme in parallel, are shown in Figures 4 and 5. In Figure $4, A, B$, and $C$ show gradient profiles of whole myotube, intracellular, and external globular forms. In Figure 5, $A, B$, and $C$ show gradient profiles of the corresponding asymmetric forms. The results shown in Figures 4 and 5 are typical of the experimental results quantitated in Tables III to V and show clearly that each globular and asymmetric form is predominantly intracellular in 8-day cultures of embryonic rat myotubes.

Quantitation of the molecular forms comprising whole myotube, external, and intracellular AChE. Our data on the composition of whole myotube, external, and intracellular AChE are summarized quantitatively in Table III. It is evident that external and intracellular AChE have different compositions. The external enzyme is composed of relatively more $10 \mathrm{~S}$, asymmetric, and nonextractable AChE and relatively less 4 S AChE. Our data on whole myotube $\mathrm{AChE}$ are in good agreement with the qualitative data presented in earlier studies (Rieger et al., 1980; Koenig and Vigny, 1978).

To determine quantitatively how the total AChE in rat myotubes is distributed among the various components of the intracellular and external compartments, the percentages describing the composition of external $\mathrm{AChE}$ (Table III) were multiplied by 0.262 (the fraction of external enzyme, Table I) and the percentages describing the composition of intracellular AChE were multiplied by 0.738 (the fraction of intracellular enzyme, Table I). The composition of whole myotube AChE then was calculated by summing the external and intracellular components. The results of these calculations are shown in Table IV. Note that the composition of whole myotube activity calculated indirectly from our composite data on intracellular and external AChE (Table IV) is in excellent agreement with that obtained independently by direct measurement of whole myotube AChE (Table III). Table IV succinctly summarizes the results of our evaluation of the cellular localization of the forms of AChE in cultured rat myotubes and shows that each globular and asymmetric form is predominantly intracellular.

In Table V, the data in Table IV have been rearranged to show quantitatively how the various forms of $\mathrm{AChE}$ 
TABLE IV

Cellular localization of the molecular forms of AChE in cullured embryonic rat myotubes

Each component is expressed as a percentage of total AChE. The compositions of external and intracellular $\mathrm{AChE}$ were calculated from the data in Table III as described under "Results." The composition of whole myotube $\mathrm{AChE}$ was calculated by summing the external and intracellular components. The percentages tabulated are based on three to six measurements of 8-day cultures derived from 20-day rat embryos.

\begin{tabular}{|c|c|c|c|}
\hline & Whole Myotube & External & Intracellular \\
\hline & \multicolumn{3}{|c|}{$\%$ whole myotube activity } \\
\hline Globular & 72.6 & 14.5 & 58.1 \\
\hline $10 \mathrm{~S}$ & 21.7 & 6.8 & 14.9 \\
\hline $4 \mathrm{~S}$ & 50.9 & 7.7 & 43.2 \\
\hline Asymmetric & 21.0 & 8.3 & 12.7 \\
\hline $16 \mathrm{~S}$ & 7.3 & 3.0 & 4.3 \\
\hline $12.5 \mathrm{~S}$ & 6.2 & 2.7 & 3.5 \\
\hline Other & 7.5 & 2.6 & 4.9 \\
\hline Nonextractable & 6.4 & 3.4 & 3.0 \\
\hline Total & 100.0 & 26.2 & 73.8 \\
\hline
\end{tabular}

TABLE V

Distribution of the molecular forms of AChE between the external and intracellular compartments of cultured embryonic rat myotubes Percentages were calculated from Table IV and are based on three to six measurements of 8-day cultures derived from 20-day rat embryos.

\begin{tabular}{lccc}
\hline & External & Intracellular & Total \\
\hline Globular & & \% form & \\
$10 \mathrm{~S}$ & 20.0 & 80.0 & 100.0 \\
$4 \mathrm{~S}$ & 31.3 & 68.7 & 100.0 \\
& 15.1 & 84.9 & 100.0 \\
Asymmetric & 39.5 & 60.5 & \\
16 S & 41.1 & 58.9 & 100.0 \\
$12.5 \mathrm{~S}$ & 43.5 & 56.5 & 100.0 \\
Other & 34.7 & 65.3 & 100.0 \\
& & & \\
Nonextractable & 53.1 & 46.9 & 100.0 \\
\hline
\end{tabular}

are distributed between the intracellular and external compartments of cultured rat myotubes. It is evident in Table $\mathrm{V}$ that a very large percentage of the $4 \mathrm{~S}$ form is intracellular (85\%) and that substantial, though smaller, percentages of the $10 \mathrm{~S}(69 \%), 16 \mathrm{~S}(59 \%)$, and $12.5 \mathrm{~S}$ $(56 \%)$ forms are intracellular.

\section{Discussion}

In adult skeletal muscle, AChE is localized in a high concentration at the neuromuscular junction where it functions to terminate neuromuscular transmission by rapidly hydrolyzing released acetylcholine. In the rat, 26 to $40 \%$ of the AChE activity is associated specifically with endplates; the balance is distributed throughout the muscle as nonendplate enzyme (Hall, 1973; Vigny et al., 1976; Younkin et al., 1982). The nonendplate enzyme in rat skeletal muscle is composed almost entirely of globular $10 \mathrm{~S}\left(\mathrm{G}_{4}\right)$ and $4 \mathrm{~S}\left(\mathrm{G}_{1}\right)$ forms (Hall, 1973; Vigny et al., 1976; Bon et al. 1979; Younkin et al., 1982), although asymmetric forms clearly comprise a small component of the nonendplate AChE in the rat diaphragm (Sketelj and
Brzin, 1980; Younkin et al., 1982). The asymmetric forms of AChE are of particular interest because they are highly concentrated in the endplate region of adult rat skeletal muscle (Hall, 1973; Vigny et al., 1976; Younkin et al., 1982 ) and appear to comprise virtually all (at least $84 \%$ ) of the external AChE that is associated specifically with endplates (Younkin et al., 1982). There is good evidence that the external enzyme at the neuromuscular junction is associated with the junctional basal lamina (Hall and Kelly, 1971; Betz and Sakmann, 1973; McMahan et al., 1978; Sketelj and Brzin, 1979), and it has been proposed that the collagen-like tail of the asymmetric forms is involved in this association (Massoulie, 1980). Some of the external asymmetric AChE at the neuromuscular junction may be integrated covalently into the junctional basal lamina because part (39\%) of this component cannot be extracted using conventional procedures (Younkin et al., 1982).

Innervation has a profound influence on the endplate and nonendplate AChE in rat skeletal muscle. Both endplate and nonendplate AChE decrease dramatically after denervation (Guth et al., 1964, 1967; Drachman, 1972; Hall, 1973; Davey and Younkin, 1978; Collins and Younkin, 1982), and both recover when reinnervation occurs at either the original or an ectopic site (Guth and Brown, 1965; Vigny et al. 1976; Weinberg and Hall, 1979). The available cvidence suggests that the influence of innervation on nonendplate $\mathrm{AChE}$ is mediated by the activity (electrical and/or mechanical) set up in muscle by nerve and that the influence of innervation on endplate AChE (the asymmetric forms in particular) is mediated in part by activity and in part by another mechanism (Drachman, 1972; Davey and Younkin, 1978; Davey et al., 1979; Fernandez et al., 1979, 1980; Rubin et al., 1980; Lomo and Slater, 1980; Ranish et al., 1980).

Cultured embryonic rat myotubes appear to be excellent cells for studying the effect of electromechanical activity on $\mathrm{AChE}$ and on the asymmetric forms of $\mathrm{AChE}$ in particular. When myoblasts derived from the innervated leg musculature of 18-day rat embryos are cultured, they begin to fuse, forming myotubes in 3 days, and the myotubes begin to fibrillate spontaneously in 5 days. Prior to fibrillation, the newly formed myotubes contain globular forms of AChE but no asymmetric forms. Asymmetric forms develop after fibrillation begins. If fibrillation is blocked after asymmetric forms have developed, these forms disappear with a half-time of about 1 day. This effect is reversible; after removal of tetrodotoxin, asymmetric forms return to normal in about 2 days (Rieger et al., 1980). The leg musculature of 14-day rat embryos is not innervated. Myoblasts from embryos at this stage fuse to form myotubes which fibrillate in culture, but these myotubes do not develop asymmetric forms unless they are co-cultured with spinal cord neurons (Koenig and Vigny, 1978). When the AChE in fibrillating myotubes derived from 18-day rat embryos is inactivated irreversibly with diisopropyl fluorophosphate, the $4 \mathrm{~S}\left(\mathrm{G}_{1}\right)$ form recovers first, followed by the 10 $\mathrm{S}\left(\mathrm{G}_{4}\right)$ form, and finally the $16 \mathrm{~S}\left(\mathrm{~A}_{12}\right)$ form. Recovery appears to be complete in about 2 days.

The aim of our study was to obtain quantitative data on the cellular localization of the asymmetric and globular forms of AChE in cultured embryonic rat myotubes. 
We first used three different methods to measure the activity of external and intracellular AChE. The results obtained with these three methods (Table I) are in excellent agreement and indicate that $26.2 \%$ of the enzyme activity in cultured rat myotubes is external and $73.8 \%$ is intracellular. We then isolated intracellular and external AChE, sequentially extracted the globular and asymmetric forms in the intracellular and external pools, and evaluated the individual globular and asymmetric forms in these pools by velocity sedimentation on sucrose gradients. Intracellular and external $\mathrm{AChE}$ were isolated using relatively simple procedures in which either external or intracellular enzyme was inactivated selectively with MSF. Our control experiments indicate that sulfonylated enzyme does not reactivate under a wide variety of experimental conditions; therefore, the techniques developed in this study should be useful for further characterizing the external and intracellular AChE in cultured embryonic rat myotubes and for characterizing the enzyme in other types of cultured cells. Tables III to V summarize the quantitative description of the cellular localization of the forms of AChE in cultured rat myotubes that has emerged from this study.

Previous studies have investigated the cellular localization of the molecular forms of AChE in three other mammalian systems: T28 cells (mouse neuroblastoma $X$ sympathetic ganglion cell hybrids; Lazar and Vigny, 1980; Taylor et al., 1981), PC12 cells (Inestrosa et al., 1981), and the adult rat diaphragm (Younkin et al., 1982). Several useful generalities emerge when our results and the results of these studies are considered together. In each of the four types of mammalian cells that have been studied, the $4 \mathrm{~S}$ form is the most abundant form of the enzyme, the $10 \mathrm{~S}$ form is less abundant, and the asymmetric forms are least abundant. Invariably, a large percentage of total AChE (45 to $75 \%$ ) is intracellular. In each cell type, a high percentage of the $4 \mathrm{~S}$ form (75 to $94 \%)$ is intracellular, and smaller percentages of the $10 \mathrm{~S}$ (11 to 69\%) and asymmetric forms (10 to 60\%) are intracellular (note that T28 cells do not contain asymmetric forms). The $4 \mathrm{~S}$ form of the enzyme always constitutes most (60 to $90 \%$ ) of the intracellular enzyme, and the 10 $\mathrm{S}$ and asymmetric forms are invariably minor components of this pool. The $4 \mathrm{~S}$ form always contributes less to the external than to the intracellular pool of $\mathrm{AChE}$, and the $10 \mathrm{~S}$ and asymmetric forms are invariably major components of the external pool.

The unique feature of the $\mathrm{AChE}$ in embryonic rat myotubes is that an unusually large percentage of the 10 $\mathrm{S}$ and asymmetric forms is intracellular. Our results indicate that $69 \%$ of the $10 \mathrm{~S}$ enzyme, $60 \%$ of the total asymmetric enzyme, and $59 \%$ of the $16 \mathrm{~S}\left(\mathrm{~A}_{12}\right) \mathrm{AChE}$ are intracellular. A much smaller percentage of the $10 \mathrm{~S}$ enzyme was found to be intracellular in T28 cells (11\%; Taylor et al., 1981), in PC12 cells (34\%) (Inestrosa et al., 1981 ), and in the adult rat diaphragm (34\%) (Younkin et al., 1982). In PC12 cells, no more than $10 \%$ of the $16 \mathrm{~S}$ enzyme appears to be intracellular (Inestrosa et al., 1981). In adult rat diaphragm (Younkin et al., 1982), only $30 \%$ of the total asymmetric forms appears to be intracellular.

The generalizations described above concerning the cellular localization of the molecular forms of AChE in mammalian cells suggest that the metabolism of $\mathrm{AChE}$ is a process in which the enzyme is synthesized and then assembled intracellularly into $10 \mathrm{~S}\left(\mathrm{G}_{4}\right)$ and asymmetric forms that are externalized (Younkin et al., 1982). Our finding that large percentages of the $10 \mathrm{~S}$ and asymmetric forms in cultured embryonic rat myotubes are intracellular provides particularly strong support for this concept but does not prove it. Additional experimentation is needed to rule out the possibility that the $10 \mathrm{~S}$ and asymmetric forms are assembled externally and then internalized and accumulated in the intracellular compartment. The AChE that is externalized by mammalian cells consists of globular forms (primarily $10 \mathrm{~S}$ ) that are secreted (Inestrosa et al., 1977; Lazar and Vigny, 1980; Carter and Brimijoin, 1981), giobular forms that are integral sarcolemmal proteins (McLaughlin et al., 1978; Lazar and Vigny, 1980), and asymmetric forms that appear to be associated with the basal lamina surrounding each muscle fiber (Hall and Kelly, 1971; Betz and Sakmann, 1973; McMahan et al., 1978; Sketelj and Brzin, 1979). The finding that unusually large percentages of the $10 \mathrm{~S}$ and asymmetric enzyme are intracellular in rat myotubes suggests that these cells will be particularly useful for evaluating the intracellular metabolism of the various $10 \mathrm{~S}$ and asymmetric forms that are externalized.

\section{References}

Anglister, L., and I. Silman (1978) Molecular structure of elongated forms of electric eel acetylcholinesterase. J. Mol. Biol. 125: 293-311.

Betz, W., and B. Sakmann (1973) Effects of proteolytic enzymes on functions and structure of frog neuromuscular junctions. J. Physiol. (Lond.) 230: 673-688.

Bloch, R. J. (1979) Dispersal and reformation of acetylcholine receptor clusters of cultured rat myotubes treated with inhibitors of energy metabolism. J. Cell Biol. 82: 626-643.

Bon, S., M. Huet, M. Lemonnier, F. Rieger, and J. Massoulie (1976) Molecular forms of Electophorus acetylcholinesterase. Molecular weight and composition. Eur. J. Biochem. 68: 523530.

Bon, S., M. Vigny, and J. Massoulie (1979) Asymmetric and globular forms of acetylcholinesterase in mammals and birds. Proc. Natl. Acad. Sci. U. S. A. 76: 2546-2550.

Carson, S., S. Bon, M. Vigny, J. Massoulie, and M. Fardeau (1979) Distribution of acetylcholinesterase molecular forms in neural and non-neural sections of human muscle. FEBS Lett. 97: 348-352.

Carter, J. L., and S. Brimijoin (1981) Effects of acute and chronic denervation on release of acetylcholinesterase and its molecular forms in rat diaphragms. J. Neurochem. 36: 10181025.

Collins, P. L., and S. G. Younkin (1982) Effect of denervation on the molecular forms of acetylcholinesterase in rat diaphragm. J. Biol. Chem, in press.

Davey, B., and S. G. Younkin (1978) Effect of nerve stump length on cholinesterase in denervated rat diaphragm. Exp. Neurol. 59: 168-175.

Davey, B., L. H. Younkin, and S. G. Younkin (1979) Neural control of skeletal muscle cholinesterase: A study using organ-cultured rat muscle. J. Physiol. (Lond.) 289: 501-515.

Drachman, D. B. (1972) Neurotrophic regulation of muscle cholinesterase: Effects of botulinum toxin and denervation. J. Physiol. (Lond.) 226: 619-627.

Fernandez, H. L., M. J. Duell, and B. W. Festoff (1979) Neurotrophic control of $16 \mathrm{~S}$ acetylcholinesterase at the vertebrate neuromuscular junction. J. Neurobiol. 10: 441-454.

Fernandez, H. L., M. R. Patterson, and M. J. Duell (1980) Neurotrophic control of $16 \mathrm{~S}$ acetylcholinesterase from mam- 
malian skeletal muscle in organ culture. J. Neurobiol. 11: 557-570.

Fluck, R. A., and R. C. Strohman (1973) Acetylcholinesterase activity in developing skeletal muscle cells in vitro. Dev. Biol. 33: $417-428$.

Guth, L., and W. C. Brown (1965) The sequence of changes in cholinesterase activity during reinnervation of muscle. Exp. Neurol. 12: 329-336.

Guth, L., R. W. Albers, and W. C. Brown (1964) Quantitative changes in cholinesterase activity of denervated muscle fibers and sole plates. Exp. Neurol. 10: 236-250.

Guth, L., W. C. Brown, and P. K. Watson (1967) Studies on the role of nerve impulses and acetylcholine release in the regulation of the cholinesterase activity of muscle. Exp. Neurol. 18: $443-452$.

Hall, Z. W. (1973) Multiple forms of acetylcholinesterase and their distribution in endplate and non-endplate regions of rat diaphragm muscle. J. Neurobiol. 4: 343-361.

Hall, Z. W., and R. B. Kelly (1971) Enzymatic detachment of endplate acetylcholinesterase from muscle. Nature New Biol. 232: 62-63.

Heinemann, S. S., R. Bevan, J. Kullberg, J. Lindstrom and J. Rice (1977) Modulation of acetylcholine receptor by antibody against the receptor. Proc. Natl. Acad. Sci. U. S. A. 74: 30903094.

Inestrosa, N. C., B. U. Ramirez, and H. L. Fernandez (1977) Effect of denervation and of axoplasmic transport blockage on the in vitro release of muscle endplate AChE. J. Neurochem. 28: 941-945.

Inestrosa, N. C., C. G. Reiness, L. F. Reichardt, and Z. W. Hall (1981) Cellular localization of the molecular forms of acetylcholinesterase in rat pheochromocytoma $\mathrm{PC} 12$ cells treated with nerve growth factor. J. Neurosci. 1: 1260-1267.

Johnson, C. D., and R. L. Russell (1975) A rapid, simple radiometric assay for cholinesterase, suitable for multiple determinations. Anal. Biochem. 64: 229-238.

Koenig, J., and M. Vigny (1978) Neural induction of the 16S acetylcholinesterase in muscle cell cultures. Nature 271: 7577.

Lazar, M., and M. Vigny (1980) Modulation of the distribution of acetylcholinesterase molecular forms in a murine neuroblastoma $\times$ sympathetic ganglion cell hybrid cell line. J. Neurochem. 35: 1067-1079.

Lomo, T., and C. R. Slater (1980) Control of junctional acetylcholinesterase by neural and muscular influences in the rat. J. Physiol. (Lond.) 303: 191-202.

Massoulie, J. (1980) The polymorphism of cholinesterases and its physiological significance. Trends Biochem. Sci. 5: 160164.

McCarty, K. S., Jr., R. T. Vollmer, and K. S. McCarty (1974) Improved computer program data for the resolution and fractionation of macromolecules by isokinetic sucrose density gradient sedimentation. Anal. Biochem. 61: 165-183.

McLaughlin, J., W. K. Engel, and N. B. Reddy (1978) Subcellular analysis of the molecular forms of acetylcholinesterase in rat skeletal muscle. J. Neurochem. 31: 783-788.

McMahan, U. J., J. R. Sanes, and L. M. Marshall (1978)
Cholinesterase is associated with the basal lamina at the neuromuscular junction. Nature 271: 172-174.

Pavlic, M. R., and I. B. Wilson (1978) On the mechanism of the acceleration of methanesulfonylation of acetylcholinesterase with cationic accelerators. Biochim. Biophys. Acta 523: 101108.

Ranish, N. A., W. D. Dettbarn, and L. Wecker (1980) Nerve stump length-dependent loss of acetylcholinesterase activity in endplate regions of rat diaphragm. Brain Res. 191: 379386.

Rieger, F., J. Koenig, and M. Vigny (1980) Spontaneous contractile activity and the presence of the $16 \mathrm{~S}$ form of acetylcholinesterase in rat muscle cells in culture: Reversible suppressive action of tetrodotoxin. Dev. Biol. 76: 358-365.

Rosenberry, T. L., and J. M. Richardson (1977) Structure of $18 \mathrm{~S}$ and $14 \mathrm{~S}$ acetylcholinesterase. Identification of collagenlike subunits that are linked by disulfide bonds to catalytic subunits. Biochemistry 16: 3550-3558.

Kotundo, R. L., and D. M. Fambrough (1979) Molecular forms of chicken embryo acetylcholinesterase in vitro and in vivo. J. Biol. Chem. 254: 4790-4799.

Rotundo, R. L., and D. M. Fambrough (1980) Synthesis, transport and fate of acetylcholinesterase in culture chick embryo muscle cells. Cell 22: 583-594.

Rubin, L. L., S. M. Schuetze, C. L. Weill, and G. D. Fischbach (1980) Regulation of acetylcholinesterase appearance at neuromuscular junctions in vitro. Nature 283: 264-267.

Sketelj, J., and M. Brzin (1979) Attachment of acetylcholinesterase to structures of the motor endplate. Histochemistry 61: $239-248$.

Sketelj, J., and M. Brzin (1980) $16 \mathrm{~S}$ acetylcholinesterase in endplate-free regions of developing rat diaphragm. Neurochem. Res. 5: 653-658.

Taylor, P. B., F. Rieger, M. L. Shelanski, and L. A. Greene (1981) Cellular localization of the multiple molecular forms of acetylcholinesterase in cultured neuronal cells. J. Biol. Chem. 256: 3827-3830.

Vigny, M., S. Bon, J. Massoulie, and V. Gisiger (1979) The subunit structure of mammalian acetylcholinesterase: Cutalytic subunits, dissociating effect of proteolysis and disulphide reduction on the polymeric forms. J. Neurochem. 33: 559565.

Vigny, M., J. Koenig, and F. Rieger (1976) The motor end-plate specific form of acetylcholinesterase: Appearance during embryogenesis and reinnervation of rat muscle. J. Neurochem. 27: 1347-1353.

Weinberg, C. B., and Z. W. Hall (1979) Junctional form of acetylcholinesterase restored at nerve-free endplates. Dev. Biol. 68: 631-635.

Wilson, B. W., P. S. Nieberg, C. R. Walker, T. A. Linkhart, and D. M. Fry (1973) Production and release of acetylcholinesterase by cultured chick embryo muscle. Dev. Biol. 33: 285299.

Younkin, S. G., C. Rosenstein, P. L. Collins, and T. L. Rosenberry (1982) Cellular localization of the molecular forms of acetylcholinesterase in rat diaphragm. J. Biol. Chem., in press. 